\title{
ARTICLE \\ Peer Reading Promotion in University Libraries
}

Based on a Simulation Study about Readers' Opinion Seeking in Social Networks Yiping Jiang, Xiaobo Chi, Yan Lou, Lihua Zuo, Yeqi Chu, and Qingyi Zhuge

\section{ABSTRACT}

University libraries use social networks to promote reading; however, there are challenges to increasing the use of these library platforms, such as poor promotion and low reader participation. Therefore, these libraries need to find ways of dealing with the behavior characteristics of social network readers. In this study, a simulation experiment was developed to explore the behaviors of readers seeking book reviews and opinions on social networks. The study draws on social network theory to find the causes of students' behavior and how these affect their selection of information. Finally, it presents strategies for peer reading promotion in university libraries.

\section{INTRODUCTION}

Over the last decade, social media has made an impact on almost every aspect of daily life. University libraries have gradually accepted social media as a way of promoting their services, and almost every university library in the People's Republic of China has its own social media accounts. However, there are challenges to increasing libraries' use of social media, such as poor promotion and low reader participation. ${ }^{1}$ University libraries cannot depend only on promoting reading through readers' unenthusiastic use of social media tools, as constructive engagement with social networks requires users' participation, dominance, and construction. ${ }^{2}$ Therefore, as a baseline, university libraries must take into consideration their readers' social attributes and then make full use of the mutual cooperation and sharing mechanisms between peers so that readers can become more involved in the use of these platforms that promote reading. In the current study, a free simulation was conducted wherein participants were required to complete a preferential choice task while browsing a book review survey that was integrated with social media platforms. ${ }^{3}$ Finally, we provide some suggestions to promote reading.

\section{LITERATURE REVIEW}

\section{University Reading Promotion}

Our review of literature on the promotion of university reading reveals three main research perspectives. The first perspective focuses on libraries. There is some evidence to suggest increasing enthusiasm for reading programs within universities. ${ }^{4}$ Rodney detailed the experiences of a library at a small liberal arts university that launched a One Book, One Community program. ${ }^{5}$ Hou emphasized the dominant position of university reading in reading promotion and put forward specific promotion strategies. ${ }^{6}$ Li et al. established a subscription digital service system for reading promotion in universities that provided personalized services for users. ${ }^{7}$ The National

Yiping Jiang (jyp@zjut.edu.cn) is Associate Professor in Information and Library Science, Zhejiang University of Technology, China. Xiaobo Chi (chixiaobo@zjut.edu.cn) is Associate Professor in Information and Library Science, Zhejiang University of Technology, China. Yan Lou (jljly@zju.edu.cn) is Associate Professor in Administrative Department of Continuing Education, Zhejiang University, China. Lihua Zuo (jlily@zju.edu.cn) is Librarian at Zhejiang University of Technology, China. Yeqi Chu (cyq77@zjut.edu.cn) is Librarian at Zhejiang University of Technology, China. Qingyi Zhuge (beckygoodly@163.com) is Librarian at Zhejiang University of Technology, China. (C) 2021. 
Resource Center for The First-Year Experience and Students in Transition hosts a discussion site and has compiled a list of institutions reporting first-year summer reading programs along with a list of book titles used in the programs. ${ }^{8}$ Appalachian State University also has an active university reading program discussion list. ${ }^{9}$ College reading experience programs have the potential to bring disparate disciplines and college departments together in ways that extend student learning and engagement beyond the classroom. It could be argued that librarians are one group of natural "boundary spanners." ${ }^{10}$ Gustavus Adolphus College has compiled a lengthy list of links to universities that participate in the first-year experience. Querying this list suggests that there is a growing number of reading programs on college campuses and librarians are increasingly finding a role in their development and delivery. ${ }^{11}$

The second perspective focuses on readers. For instance, Zhou et al. analyzed users' reading needs and proposed ideas of how universities could promote reading through the use of questionnaires. ${ }^{12}$ Based on self-determination theory, Wei et al. constructed an index of students' and teachers' motivation and participation in reading promotions in libraries by using questionnaires. Their factor analysis of readers' reading psychology from the aspects of information value, social sharing, interest, cognition, and emotional entertainment concludes that the theme, intelligence, and interactivity of college reading promotions are significant. ${ }^{13}$ Dali made specific recommendations on how to give reading practices in academic libraries a boost and a new direction through the lens of the differentiated nature of readerships on campuses. ${ }^{14}$

The third perspective focuses on cultural constructions in colleges. Boff et al. studied the practical activities they termed as library participation in "campus reading experience" (CRE) at two American community colleges and two four-year institutions in the United States. ${ }^{15}$ Their research pointed out the importance of reading promotion activities in the cultural constructions of colleges and universities. Moreover, it presented efficient suggestions of how librarians can hold reading promotion activities on campus and how librarians can play a more positive role in presenting reading promotion plans to their administrations. Marcoux et al. emphasized the vital status of Canadian college libraries in various subject areas and cultural dominance in colleges and insisted that reading promotion should be enforced by bringing together colleges, teachers, and students. ${ }^{16}$

\section{Peer Education in University Libraries}

Since the 1970s, university libraries have experimented with making students an extension of reference services and part of established peer instruction services. For example, at California State University, Fresno, student assistants were recruited to work on the reference desk and answer directional and simple reference questions. ${ }^{17}$ The University of Michigan in Ann Arbor developed its peer information counseling program in 1985 to focus on the retention of minority students. ${ }^{18}$ The University of Wisconsin-Parkside and Binghamton University in New York employ student peers to provide instructional support. ${ }^{19}$ All these programs incorporate peer tutoring models developed specifically for their settings.

There are many practical projects in which libraries provide instruction to peer readers, such as the peer practical project at Wabash College, the student assistant project at Valparaiso University, the student consultant project at the University of New Mexico, the curriculum consultant project at the University of New Hampshire, and the student assistants project at Utah State University. ${ }^{20}$ Surveys of targeted students in these programs revealed that students were more likely to ask questions of student assistants than librarians. Descriptions of the training in these projects 
emphasized knowledge of the library's resources, with little or no explanation of incorporating peer-learning principles. ${ }^{21}$

By 2010, libraries acknowledge that peer learning provides an opportunity to further solidify the information literacy skills of all students. Programs such as the library instruction tutor project at the University of New Mexico and research mentors at the University of New Hampshire were designed with a focus on taking advantage of the uniqueness of the peer-to-peer relationship, rather than replacing reference services. ${ }^{22}$ The LibRAT program at California Polytechnic State University trained students to provide single-shot information literacy instruction. Student endorsement of peer-led sessions provides supportive evidence that participating attendees perceive this type of session as useful and valuable. ${ }^{23}$

To summarize, university libraries have identified that harnessing the uniqueness of peer relationships is an effective way to engage students in learning. ${ }^{24}$

\section{Social Reading Promotion}

The first published papers regarding the use of Facebook by libraries and librarians appeared in $2006 .{ }^{25} \mathrm{Up}$ to that time, most scholars defined social reading as sharing theoretical research but had not yet explored its relationship to social media. For instance, Zhang et al. suggested that classic books and other resources should be aimed more accurately at potential users, and the convenience of the connection between a library and its users in the social media environment should be fully utilized in order to understand the personal needs of users. ${ }^{26}$ Yang et al. explored the relationship between users who engage in social reading and reading resources by analyzing it from the perspective of users. ${ }^{27}$ White et al. explored how social networks promote reading and studying and found that social media can promote users' selection, critiques, and discussions in the reading context, which are part of the process of constructive studying. ${ }^{28}$ Similarly, Asteman et al. investigated the impact of users' discussions on reading participation and reading promotion by using Facebook as a research target, and they proved that users' discussions on social reading were beneficial to reading, studying, and understanding complex scientific topics. ${ }^{29}$

Some researchers have explored the resources recommending methods and algorithms for social reading. Take Kochitchi et al.'s research as an example: they built a visual analysis system to construct the relationship between user characteristics and resources by extracting social reading tags and user interaction behavior characteristics. ${ }^{30}$ Huang et al. proposed an efficient method for recommending information among social network groups. ${ }^{31}$

Some scholars put particular emphasis on researching user services. For instance, Liu et al. created reading review flows to help improve users' reading ability and optimize the reading experience by analyzing users' needs on social platforms. ${ }^{32}$ Fox subdivided users on social media platforms into three categories-passive, active, and interactive-and summarized that users' standardized behaviors can effectively enhance user interaction. ${ }^{33}$ Yao et al. studied the data gathered from practical activities such as information posts and book retrieval through social reading platforms at the Tsinghua University Library. ${ }^{34}$ 


\section{METHODS}

\section{Research Questions}

Existing studies on social reading promotion in libraries have mainly explored how to use social media platforms to promote and develop reading promotion services. However, few scholars have explored the reader patterns of those seeking opinions within social networks. This study explored the effects that peers have on each other as opposed to services provided by university libraries and addressed the following three questions:

1. Do readers value the opinions of peers on social networks?

2. What tendencies do readers exhibit when seeking opinions on different types of literature?

3. How does social capital influence readers' tendencies when those readers are seeking opinions?

Social capital refers to the potential value of social relations and includes two key dimensions: structural and relational. ${ }^{35}$ Social structure can be characterized by quantity and configuration. ${ }^{36}$ With respect to quantity, the more social ties one has the potential to activate, the more information resources can be transferred. ${ }^{37}$ The configuration of social capital means that it is higher when a network's structure is more sparse. ${ }^{38}$ Relational capital refers to the potential value associated with the quality of social relationships which are created and embedded by network peers and can be utilized by network friends. ${ }^{39}$ Previous studies have used different social attributes to describe relational capital, including homogeneity, trust, expertise, power, and closeness. ${ }^{40}$

\section{Study design}

We used a questionnaire applet and designed a survey of book reviews to explore patterns in the way readers seek information on books through social networks and the factors that influence readers when they adopt others' opinions.

As an initial step, we recruited 300 college student participants from 15 colleges and universities. These students, from the WeChat group of The Eighth National Mechanical Design Competition for College Students, expressed interest in the study. The students were offered three lists of books, categorized as leisure literature, mechanical literature, and information resources utilization literature. There were 10 books in every list, and the books were selected from a 2019 lending list compiled by five colleges and universities.

Participants were asked to log in to our survey using their WeChat credentials. They were required to write reviews for the books that they had read, and they were encouraged to recommend similar literature and write reviews for those books as well. Meanwhile, 30 librarians were also invited to write reviews for the books on the lists (see fig. 1). 


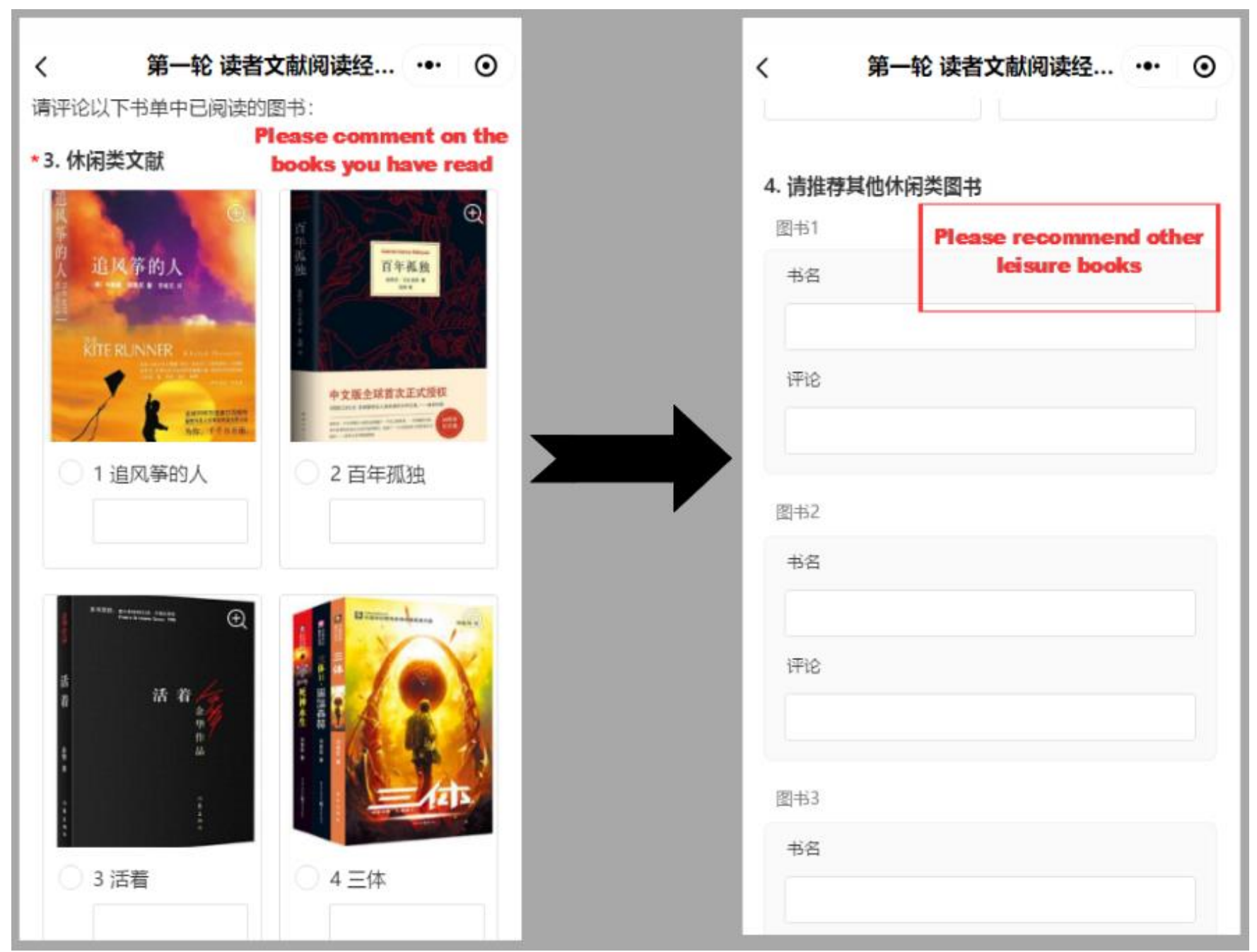

Figure 1. The book review steps.

To keep a representative sample, we adopted stratification and divided participants into different non-overlapping homogenous groups. We set up six groups with similar scales according to the number of WeChat friends that the readers had within the 300-student sample. Readers in the first group did not have any friends. Readers in the second group had one or two friends. Readers in the third group had three or four friends. Readers in the fourth group had five or six friends. Readers in the fifth group had seven to eleven friends. Readers in the sixth group had twelve or more friends. Subsequently, we randomly invited 15 readers from every group to complete the following steps: (1) complete an online questionnaire that measured their relational capital (see table 1 and fig. 2) and (2) make references to others' reviews and select books that they intended to read (see fig. 2). 
Table 1. Three measurements of relational capital

\begin{tabular}{|c|c|}
\hline Measurements & Questionnaire \\
\hline Professional skills & $\begin{array}{l}\text { 1. Reading is a part of my life. } \\
\text { 2. Reading is in my daily to-do list. } \\
\text { 3. I go to the library to study. } \\
\text { 4. My reading ability is good. } \\
\text { 5. Reading helps me a lot. } \\
\text { 6. I read a lot (at least } 10 \text { books a year) }\end{array}$ \\
\hline Similarity & $\begin{array}{l}\text { 1. My friends and I read similar books. } \\
\text { 2. My friends and I have similar feelings about } \\
\text { reading. } \\
\text { 3. Recommendations are useful to me. }\end{array}$ \\
\hline Intimacy & $\begin{array}{l}\text { 1. My survey group is trustworthy. } \\
\text { 2. Others' comments are beneficial to me. } \\
\text { 3. I am willing to share my feelings about reading with } \\
\text { my friends. }\end{array}$ \\
\hline
\end{tabular}

Note: A five-point Likert scale (strongly disagree, disagree, neutral, agree, strongly agree) was used. 


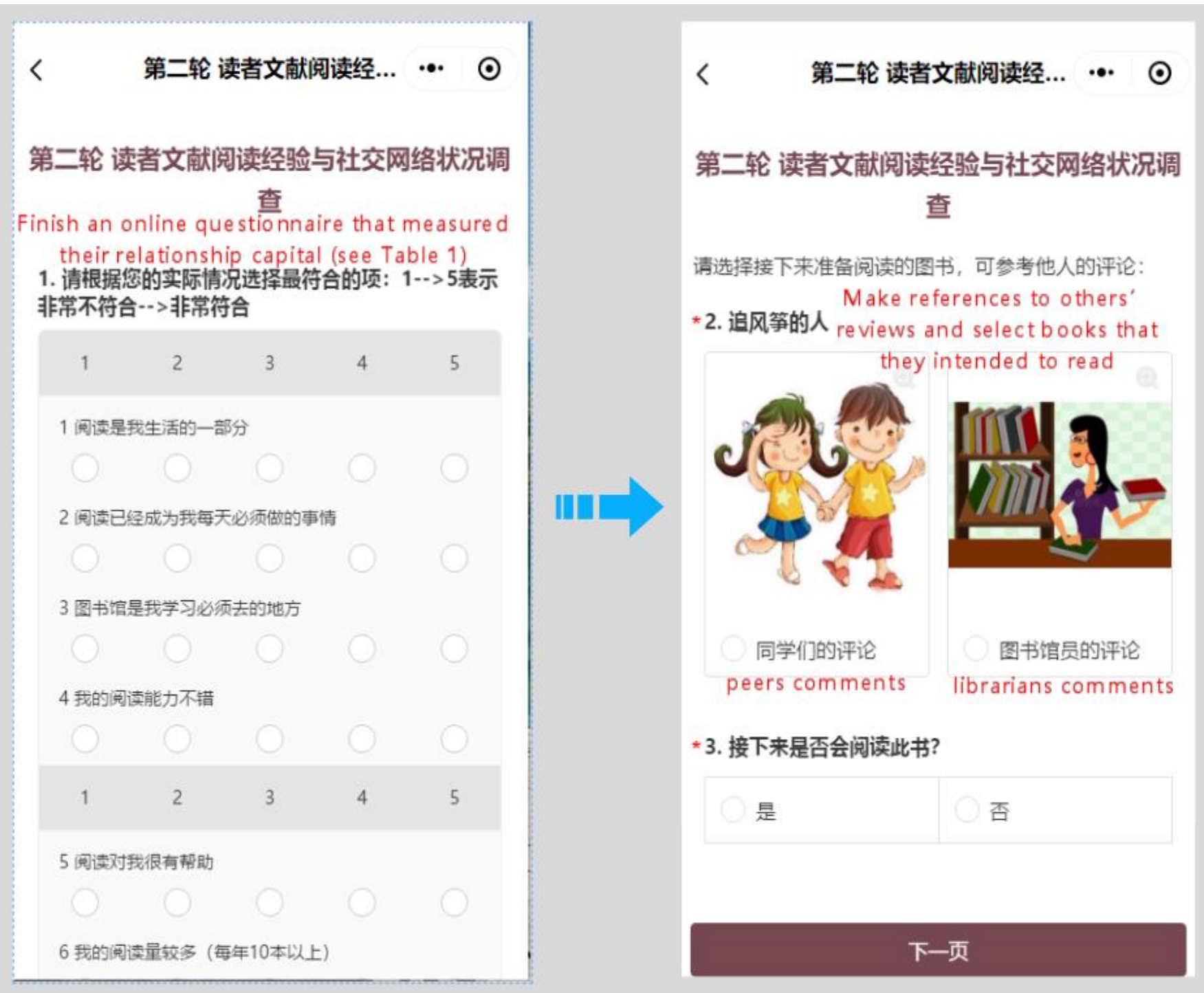

Figure 2. Selecting the books.

\section{Data Collection}

Measurement of readers' behavior when seeking opinions. A book review applet (with WeChat's questionnaire function) was incorporated to record the number of times a reader looked at reviews from peers and librarians (see fig. 3). 


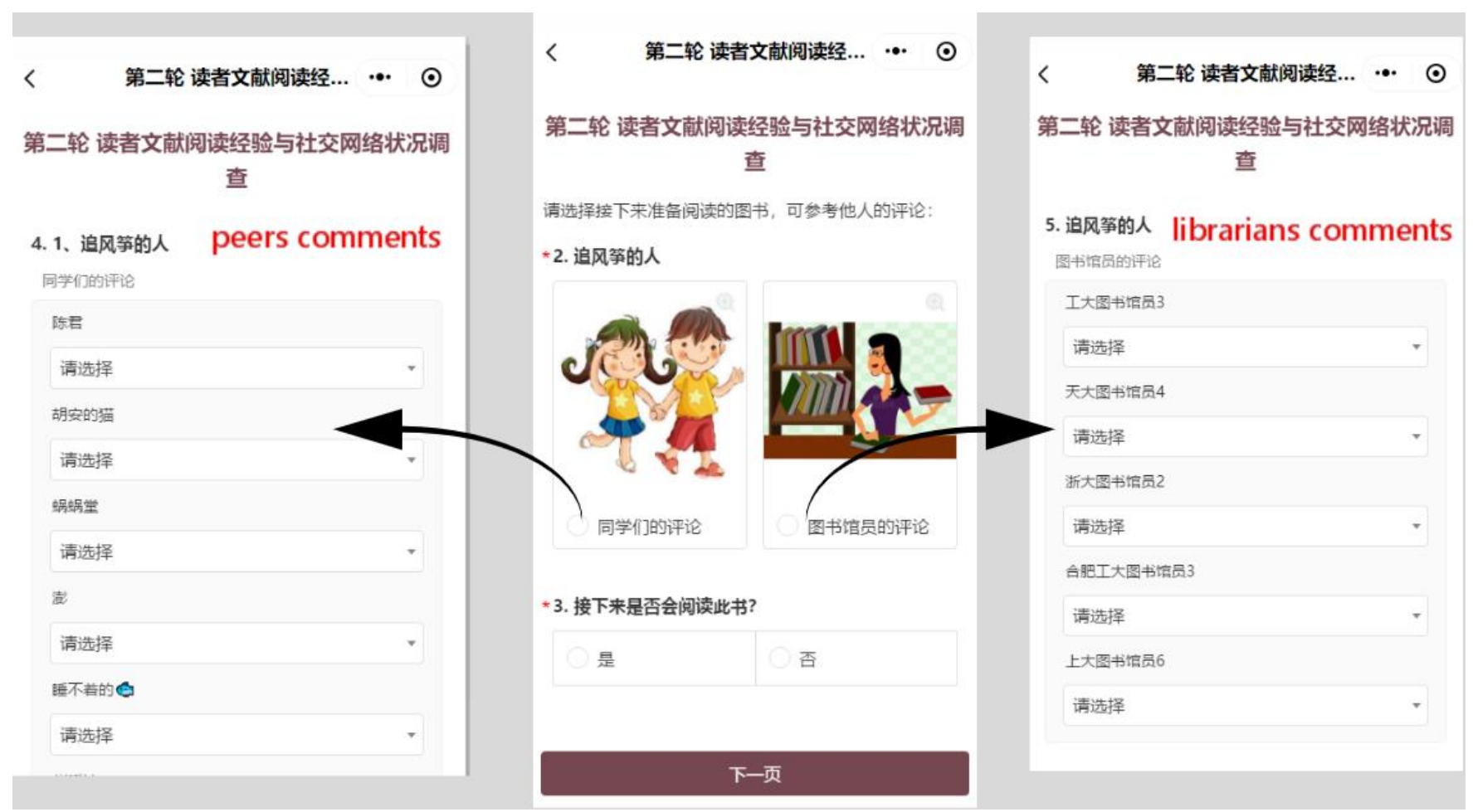

Figure 3. Measurement of readers' behavior when seeking opinions.

Note: When readers wanted to refer to other people's comments, the applet allowed them to choose either classmates' or librarians' reviews. Readers could browse the comments through a drop-down menu, and the number of reviews read by the respondents was recorded.

Measurement of structural capital. The scale of a reader's structural capital was related to the number of WeChat friends they had. ${ }^{41}$ Drawing on the extant literature, we computed network sparseness by dividing the network's effective size by the overall size. Network effective size is the average number of WeChat friends within the sample set of 300 people.

Measurement of relational capital. We used the three variables of professional skills, similarity, and intimacy to measure social relationships. ${ }^{42}$ Data were gathered from the online questionnaire (see table 1).

\section{Experiment Validity}

Reliability analysis. We performed measurement validity checks on the three variables applied in the measurement of relational capital. Table 2 shows the evidence of satisfactory convergence and discriminant validity.

Table 2. Reliability analysis results

\begin{tabular}{|l|l|l|}
\hline Cronbach's Alpha & Std. Cronbach's Alpha & Projects \\
\hline .811 & .811 & 12 \\
\hline
\end{tabular}

Factor analysis. We tested whether it was scientifically meaningful to consider network scale, network sparseness, and relational capital as independent variables in respectively analyzing two 
dependent variables, that is, times of seeking peers' opinions and times of referring to librarians' opinions. Tables 3 and 4 show the results of the Kaiser-Meyer-Olkin (KMO) spherical test and Bartlett's test, which show that factor analysis is suitable, and further analysis can be performed.

Table 3. KMO spherical test

\begin{tabular}{|l|l|r|}
\hline KMO & \multicolumn{2}{|}{.654} \\
\hline Bartlett's test & chi-square & 314.342 \\
\hline & df & 10 \\
\hline & Significance & .00 \\
\hline
\end{tabular}

Table 4. Bartlett's test

\begin{tabular}{|l|c|c|}
\hline & Initial & Extract \\
\hline Network scale & 1.000 & .724 \\
\hline Network sparseness & 1.000 & .676 \\
\hline Relational capital & 1.000 & .720 \\
\hline
\end{tabular}

\section{RESULTS}

\section{Reviews Written and Browsed}

We recorded the number of reviews read by the respondents and then compared the number of times they consulted peers with the number of times they consulted librarians. The results are shown in table 5. In total, readers sought opinions from peers 1,374 times (70.9\%), and from librarians 563 times (29.1\%). For leisure literature, mechanical literature, and information resources utilization literature they sought opinions from peers 422 times (85.3\%), 519 times (88.3\%), and 433 times (50.7\%), respectively. From these results, it can be surmised that readers tend to seek opinions from peers.

Table 5. Comparison of sources consulted by readers seeking opinions

\begin{tabular}{|l|l|l|l|l|}
\hline & \multicolumn{1}{|c|}{ Leisure } & \multicolumn{1}{|c|}{ Mechanical } & $\begin{array}{c}\text { Information } \\
\text { resources } \\
\text { utilization }\end{array}$ & Total \\
\hline & Reviews browsed & Reviews browsed & Reviews browsed & \\
\hline Readers & $422(85.3 \%)$ & $519(88.3 \%)$ & $433(50.7 \%)$ & $1374(70.9 \%)$ \\
\hline Librarians & $73(14.7 \%)$ & $69(11.7 \%)$ & $421(49.3 \%)$ & $563(29.1 \%)$ \\
\hline
\end{tabular}

We used regression analysis to analyze the relationship between readers' behavior of seeking opinions and social capital. Results are shown in table 6 . According to the t-test, given the significance level of 0.10 , the significance probability of the three variables was less than 0.10 for both the times that readers sought peer opinions and the times that they consulted librarians. Table 7 shows the introduction and elimination process of variables in the process of stepwise 
regression. The analysis of seeking peer opinions eliminates relational capital, and the analysis of reference to librarians' opinions has eliminated network sparseness.

Table 6. Regression analysis results

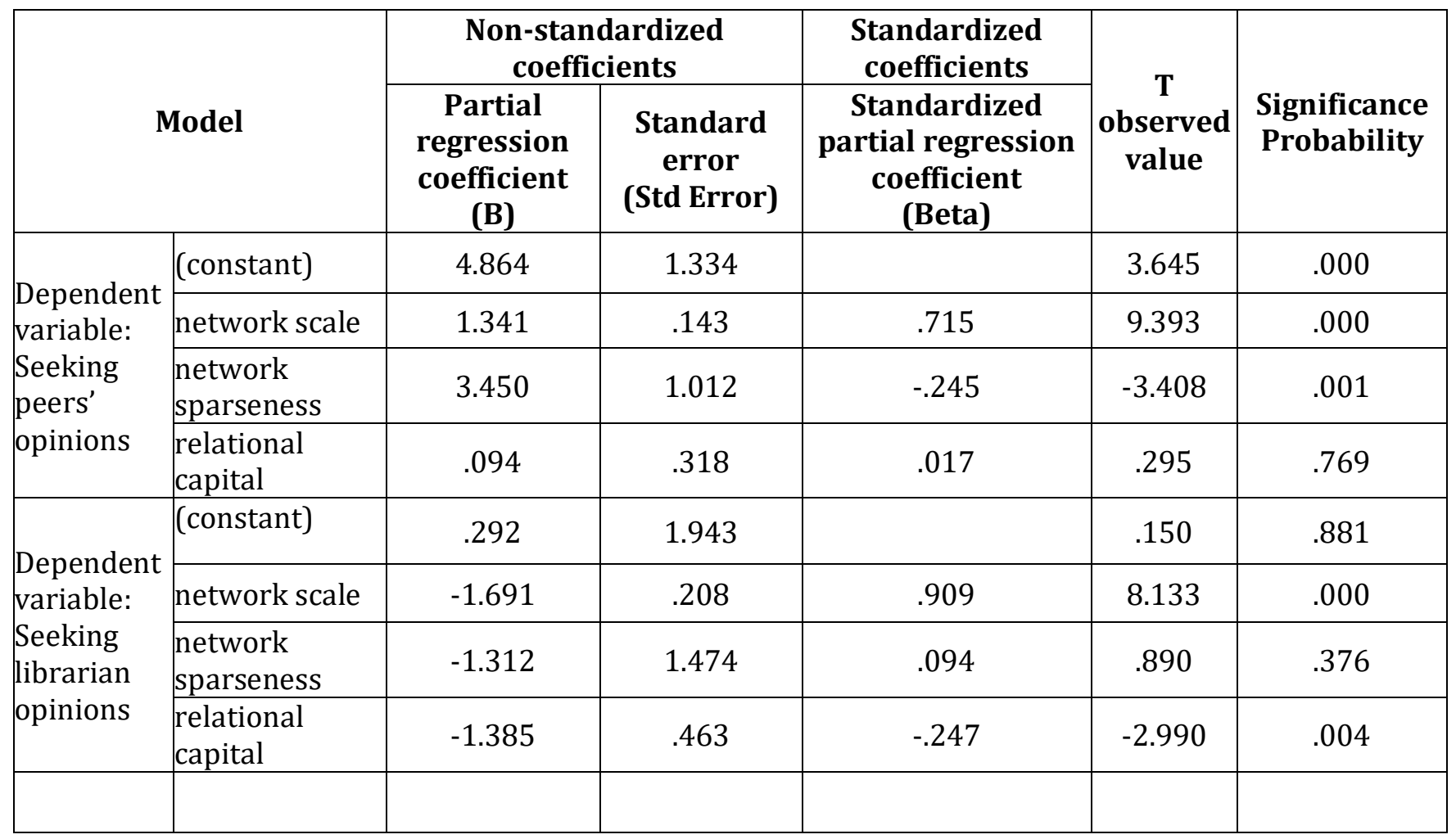

Table 7. Quantity introduction and elimination process

\begin{tabular}{|l|l|l|}
\hline Model & Variable entered & Variable removed \\
\hline $\begin{array}{l}\text { Dependent variable: } \\
\text { seeking peers' opinions }\end{array}$ & $\begin{array}{l}\text { network scale, network } \\
\text { sparseness }\end{array}$ & relational capital \\
\hline $\begin{array}{l}\text { Dependent variable: } \\
\text { seeking librarians' } \\
\text { opinions }\end{array}$ & $\begin{array}{l}\text { network scale, relational } \\
\text { capital }\end{array}$ & network sparseness \\
\hline
\end{tabular}

According to the analysis results, we can draw some conclusions. First, the number of times readers sought opinions from peers was in proportion to network sparseness. In other words, the higher the number of readers' online peers, the lower the network sparseness and the more they sought advice from their peers. Second, the number of times readers sought librarians' opinions was inversely proportional to their network scale and relational capital. This means that readers tended not to seek opinions from librarians if they had more network peers and more relational capital. 
According to further analysis of tables 6 and 7, there are two equations that can derived:

1. Regression equation of readers seeking opinions from peers:

$$
\mathrm{y}_{1}=4.864+1.341 \mathrm{x}_{1}+3.450 \mathrm{x}_{2}
$$

where $\mathrm{y}_{1}$ represents seeking peer opinions and $\mathrm{x}_{1}$ and $\mathrm{x}_{2}$ represent network scale and network sparseness, respectively.

2. Regression equation of readers seeking opinions from librarians:

$$
\mathrm{y}_{2}=0.292-1.691 \mathrm{x}_{1}-1.385 \mathrm{x}_{3}
$$

where $\mathrm{y}_{2}$ represents seeking librarian opinions and $\mathrm{x}_{1}$ and $\mathrm{x}_{3}$ represent network scale and relational capital, respectively.

Based on the two regression equations, it can be observed that the number of peers' reviews consulted increases by $13.9 \%$ for each point increase in network scale and by $35.7 \%$ for each additional unit of network sparseness. The number of librarians' reviews consulted decreases by $60.7 \%$ for each point increase in network scale and by $70.7 \%$ for each additional unit of relational capital.

\section{DISCUSSION}

\section{The Value of Peers}

According to the results in table 5, readers tend to seek opinions from peers. This is mainly because familiar information sources can provide more diagnostic help. ${ }^{43}$ Meanwhile, the cognitive effort required to process such information is lower and information is easier to understand. Research on peer education also shows similar findings. Jane Piaget and Lev Vygotsky found that it is easier to build partnerships among children than among children and adults. Moreover, children are more willing to negotiate and theorize with partners who are not authoritative. In this social media age, the value of peers is even more pronounced. Therefore, libraries should recognize this, recruit influential readers for reading promotion, and utilize the influence of peer social networks to spread information related to the promotion of reading.

\section{Opinion Seeking Tendency of Different Types of Literature Information}

The participants in this study were university students majoring in mechanical engineering disciplines across several different universities. This means that they had similar backgrounds, experiences, and feelings as they participated in the mechanical design competition. Under these circumstances, it would be expected that they had close peer relationships. Behavioral science research proves that if the communicator and the receiver have similar experiences, are concerned about similar things, and face similar problems, the receiver is more likely to accept information from the communicator. This viewpoint is consistent with the standpoint proposed by psychological models in which relevant sources of information are more frequently activated. ${ }^{44}$ Therefore, the result that readers are more willing to seek opinions from peers is supported.

The result regarding information resources utilization literature shows similar numbers in terms of seeking opinions from peers and from librarians, and the number seeking from librarians is slightly higher. This may be because libraries are the literature and information resource centers 
of universities, and readers trust the professional abilities of librarians and are willing to seek their help with regard to resource utilization. The results indicate that librarians should make efforts to promote the use of information resources.

\section{Seeking Tendency of Readers with Different Social Capital}

In the process of decision-making, readers will look for homogeneous and credible people to assist them in their search for and evaluation of information. ${ }^{45}$ Identity, experience, reading level, and taste in reading are contributing factors to credibility. The more partners, the more the relational capital; if readers have more trustworthy sources of information, they will not turn to librarians for their opinions.

Information searching is a dynamic and adaptive process. When readers find information that is novel, it has value in decision-making. Conversely, when the information is redundant (not novel), it may cause the seeker to stop searching. It is widely acknowledged that sparse social networks reduce the possibility of information redundancy. ${ }^{46}$ Therefore, the sparser the social network, the more likely it is that readers will need peer help.

\section{CONCLUSIONS}

In this age of social media, university students are accustomed to using social networks. Seeking information that complies with their psychological needs is more significant and valuable to them than the value of the information itself. Therefore, libraries should make full use of peer influences when employing social media in reading promotion activities.

First, university libraries ought to realize their great potential for involving students within the social flow to participate in reading promotion activities. In the digital age, readers' consciousness is repeatedly awakened. Individuality, advocating for information freedom, and improving the flow of information mean that readers are no longer satisfied with passively receiving information and are more willing to actively search out and read information. Meanwhile, sharing and interaction can fully meet the desires of individuals to share and communicate as well as meet their psychological need of realizing their self-worth. Libraries must understand the characteristics of contemporary university students' information needs and create a space for readers to take the initiative. Only in this way can readers be more than passive recipients of information-they can also be pushers and disseminators of information.

Bolder attempts at innovation should be applied to reading promotions. In this research, an analysis and exploration were conducted based on the literature, indicating that readers prefer to seek opinions from their own social networks. Therefore, the library can make full use of readers' social network groups when promoting the library's literature resources. Likewise, other services and activities provided by the libraries can be promoted through readers' social networks. For instance, libraries can invite student volunteers to take part in a new service before launching and then invite them to share their feelings and evaluations through social networks. These types of methods are more efficient than the traditional flyer notification.

Last but not least, when organizing reading promotion activities, libraries should stay behind the scenes. University libraries can establish a set of systematic peer reading promotion rules, including recruitment, training, and management systems, to build a wide and influential reading promotion student volunteer team on social networks. Libraries should, however, strengthen the process of monitoring peer reading promotions to prevent negative influences caused by harmful 
information on social media. ${ }^{47}$ They should pay special attention to the control of social opinion by using the reader volunteer team. In addition, through the monitoring and analysis of data, the strategy and direction of reading promotions can be adjusted over time to improve their pertinence and effectiveness. Moreover, libraries should strengthen the effective evaluation of peer reading promotion projects. Readers should be involved in the systematic readjustment of traditional reading promotion methods. Innovative methods need to be tested in practice so that libraries can strengthen the effective evaluation of peer projects.

\section{LIMITATIONS AND FUTURE RESEARCH}

There are some limitations in the methodology design, theoretical scope, empirical context, and research perspective in the current study. Getting past these limitations can also provide direction for further research.

In the methodology, although the sectional sampling method is often adopted, the conclusions of this research make it difficult to disentangle the roles of readers' social capital from those of opinion seeking. This study explored the correlations between several variables which need to be further investigated by introducing control variables to fully examine the interactions between the variables.

In theory, this research focused on analysis of the rule that readers will seek opinions through social networks, which reflects the behavior observed in information searching and browsing. Readers then need to decide whether to use the information they find. These two behaviors are related and, based on this research, we need to further explore readers' adoption behavior to better guide reader service work in libraries.

In the empirical analysis, it is worth further considering how the various efforts undertaken by university libraries have promoted information channels. The participants in this study were university students majoring in mechanical engineering disciplines. However, students in different majors may exhibit different information selecting behavior, and this deserves further analysis and exploration.

This study compared the influence of peers' and librarians' opinions on readers. However, how do readers feel about opinions from peers as compared to those from librarians? What is the impact of students preferring to use their social networks instead of librarians for information retrieval? Is there a difference in the adoption of peer opinions by readers in different social media contexts? These questions deserve further study to fully understand the impact of social networks on reader opinion-seeking behavior.

\section{ACKNOWLEDGEMENTS}

This work was supported by the Humanities and Social Sciences Research Fund of the Chinese Ministry of Education [grant number 17YJA870003] and the Philosophy and Social Science Fund of Zhejiang Province [grant number 21NDJC039YB]. 


\section{ENDNOTES}

${ }^{1}$ Shi-Man Tang, "Research on the Reading Promotion Model and Implementation Path of University Library Based on Social Media Platform." (master's thesis, University of Jilin, 2013): 90-111.

${ }^{2}$ Yao Qi, Hua-Wei Ma, Huan Yan, and Qi Chen, “Analysis of Social Network Users' Online Behavior from the Perspective of Psychology," Advances in Psychological Science 22, no. 10 (2014): 1647-59, https://doi.org/10.3724/SP.J.1042.2014.01647.

${ }^{3}$ David Gefen, Elena Karahanna, and Detmar W. Straub, “Trust and TAM in Online Shopping: An Integrated Model," MIS Quarterly 27, no. 1 (March 2003): 51-90, https://doi.org/10.2307/30036519.

${ }^{4}$ Colleen Boff, Robert Schroeder, Carol Letson, and Joy Gambill, “Building Uncommon Community with a Common Book: The Role of Librarians as Collaborators and Contributors to Campus Reading Programs," Research Strategies 20, (2007): 272-83, https://doi.org/10.1016/j.resstr.2006.12.004.

${ }^{5}$ Mae L. Rodney, “Building Community Partnerships: The 'One Book One Community' Experience,” C\&RL News 65, no. 3 (March 2004), 130-32, https://doi.org/10.5860/crln.65.3.130.

${ }^{6}$ Ai-hua Hou, "Analysis and Research on the Reading Promotion Strategy of University Library," Lifelong Education 9, no. 5 (2020), https://doi.org/10.18282/le.v9i5.1251.

${ }^{7}$ Mei-Ning Li, Tian-Zi Zhao, Xu Guan, and Xin-hua Chen, "Study on Building Digital Service System of 'Subscription' Reading Promotion for University Library," Library and Information Service 62, no. 18 (2018): 77-82, https://doi.org/10.13266/j.issn.0252-3116.2018.18.008.

${ }^{8}$ Boff, “Building Uncommon Community with a Common Book," 271-83.

${ }^{9}$ Kim Becnel et al., “'Somebody Signed Me Up': North Carolina Fourth-Graders' Perceptions of Summer Reading Programs," Children \& Libraries: The Journal of the Association for Library Service to Children 15, no. 3 (2017): 3-8, https://doi.org/10.5860/cal.15.3.3.

10 Rodney, "Building Community Partnerships," 130-32, 155.

${ }^{11}$ Boff, “Building Uncommon Community with a Common Book," 271-83.

$12 \mathrm{Mu}$-chen Wan and Liang Ou, "The Empirical Research of University Libraries Reading Promotion Effect Based on the WeChat Public Platform," Library and Information Service 60, no. 22 (2015): 72-78, https://doi.org/10.13266/i.issn.0252-3116.2015.22.011.

${ }^{13}$ Xiao-Li Wei, Yi-Ming Mi, and Fang Sheng, “Motivation Measurement of University Library's Participation in the Reading Promotion Based on Self-determination Theory," Journal of Library and Information Science 10, (2018): 1-8.

${ }^{14}$ Dali Keren and Lindsay McNiff, "Reading Work as a Diversity Practice: A Differentiated Approach to Reading Promotion in Academic Libraries in North America," Journal of 
Librarianship and Information Science 52, no. 4 (February 2020): 1050-62, https://doi.org/10.1177/0961000620902247.

${ }^{15}$ Boff, "Building Uncommon Community with a Common Book," 271-83.

${ }^{16}$ Elizabeth Betty Marcoux and D. V. Loertscher, "The Role of a School Library in a School's Reading Program," Teacher Librarian 37, no. 1 (2009): 8, 10-14, 84.

${ }^{17}$ Brett B. Bodemer, "They CAN and They SHOULD: Undergraduates Providing Peer Reference and Instruction," College \& Research Libraries 75, no.2 (2014): 162-78, https://doi.org/10.5860/crl12-411.

${ }^{18}$ Barbara MacAdam and Darlene P. Nichols, "Peer Information Counseling: An Academic Library Program for Minority Students," Journal of Academic Librarianship 15, no. 4 (1989): 204-9, https://doi.org/10.1016/0268-4012(89)90012-1.

${ }^{19}$ Turkey Alzahrani and Melinda Leko, "The Effects of Peer Tutoring on the Reading Comprehension Performance of Secondary Students with Disabilities: A Systematic Review," Reading \& Writing Quarterly (April 2017): 1-17, https://doi.org/10.1080/10573569.2017.1302372.

${ }^{20}$ Bodemer, "They CAN and They SHOULD," 162-78; Ruth Sara Connell and Patricia J. Mileham, "Student Assistant Training in a Small Academic Library," Public Services Quarterly 2, no. 2-3 (2006): 69-84, https://doi.org/10.1300/J295v02n02 06; Michael M. Smith and Leslie J. Reynolds, "The Street Team: An Unconventional Peer Program for Undergraduates," Library Management 29.3 (2008): 145-58, https://doi.org/10.1108/01435120810855287; Gail Fensom et al., "Navigating Research Waters: The Research Mentor Program at the University of New Hampshire at Manchester," College \& Undergraduate Libraries 13, no. 2 (2006): 49-74, https://doi.org/10.1300/J106v13n02 05; Wendy Holliday and C. Nordgren, "Extending the Reach of Librarians: Library Peer Mentor Program at Utah State University," College \& Research Libraries News, 66, no. 4 (2005), https://doi.org/10.5860/crln.66.4.7422.

${ }^{21}$ Mary O’Kelly, Julie Garrison, Brian Merry, and Jennifer Torreano, “Building a Peer-Learning Service for Students in an Academic Library," Libraries and the Academy 15, no. 1 (2015): 16382, https://doi.org/10.1353/pla.2015.0000.

${ }^{22}$ Fensom et al., "Navigating Research Waters," 49-74.

${ }^{23}$ Bodemer, "They CAN and They SHOULD," 162-78.

${ }^{24}$ Ling-Jie Yao, "Peer Education: A New Mode of University Library Services," Library Development 12, (2012): 57-59.

${ }^{25}$ Jamie M. Graham, Allison Faix , and Lisa Hartman, “Crashing the Facebook Party: One Library's Experiences in the Students' Domain," Library Review 58, no. 3 (2009): 228-36, https://doi.org/10.1108/00242530910942072.

${ }^{26}$ Yue-Qun Zhang and Chun-Ning Li, "Change of Library Role in Knowledge Transfer in Social Network Environment and Countermeasures," Library and Information 166, no. 6 (2015): 10712. 
27 Yi Yang and Ji-Qing Sun, "Professional Reading Habits Correlation Research Based on the Social Network Theory," New Century Library 70, no. 10 (2012): 81, 91-92, https://doi.org/10.16810/i.cnki.1672-514x.2012.10.024.

${ }^{28}$ John Wesley White and Holly Hungerford-Kresser, "Character Journaling through Social Networks," Journal of Adolescent \& Adult Literacy 57, no. 8 (2014): 642-54, https://doi.org/10.1002/jaal.306.

${ }^{29}$ Christa S. C. Asterhan and Rakheli Hever, "Learning from Reading Argumentative Group Discussions in Facebook," Computers in Human Behavior, no. 53 (2015): 570-76, https://doi.org/10.1016/i.chb.2015.05.020.

${ }^{30}$ A. Kochtchi, T. V. Landesberger, and C. Biemann, "Networks of Names: Visual Exploration and Semi-Automatic Tagging of Social Networks from Newspaper Articles," Computer Graphics Forum 33, no. 3 (2014): 211-20, https://doi.org/10.1111/cgf.12377.

${ }^{31}$ Zhen-Hua Huang, Bo Zhang, Qiang Fang, and Yang Xiang, "An Efficient Algorithm of Information Recommendation Between Groups in Social Networks," Acta Electronica Sinica 43, no. 6 (2015): 1090-93.

${ }^{32}$ Cheng-Ying Liu, Ming-Syan Chen, and Chi-Yao, "IncreSTS: Towards Real-Time Incremental Short Text Summarization on Comment Streams from Social Network Services," IEEE Transactions on Knowledge and Data Engineering 27, no. 11 (2015): 2986-3000, https://doi.org/10.1109/TKDE.2015.2405553.

33 Jesse Fox and Courtney Anderegg, "Romantic Relationship Stages and Social Networking Sites: Uncertainty Reduction Strategies and Perceived Relational Norms on Facebook," Cyberpsychology Behavior \& Social Networking 17, no. 11 (2014): 685-91, https://doi.org/10.1089/cyber.2014.0232.

${ }^{34}$ Fei Yao, Cheng-Yu Zhang, Wu Chen, and Tian-Fang Dou, "Study on Integrating Library Services into Social Network Sites: Taking the Book Club of Tsinghua Library University as a Practice Example," Library Journal 30, no. 6 (2011): 24-28, https://doi.org/10.13663/j.cnki.lj.2011.06.014.

${ }^{35}$ Lin Nan, "Social Capital: A Theory of Social Structure and Action," (Cambridge: Cambridge University Press, 2001); Paul S. Adler and Seok-Woo Kwon, "Social Capital: Prospects for a New Concept," Academy of Management Review 27, no. 1 (2002): 17-40, https://doi.org/10.5465/AMR.2002.5922314; Peter Moran, "Structural vs. Relational Embeddedness: Social Capital and Managerial Performance," Strategic Management Journal 26, no. 12 (2005): 1129-51, https://doi.org/10.1002/smj.486.

${ }^{36}$ Peter H. Gray, S. Parise, and B. Iyer, "Innovation Impacts of Using Social Bookmarking Systems," MIS Quarterly 35, no. 3 (2011): 629-43, https://doi.org/10.1002/asi.21581.

${ }^{37}$ Linton C. Freeman, “Centrality in Social Networks' Conceptual Clarification,” Social Networks (1978), https://doi.org/10.1016/0378-8733(78)90021-7; Stephen P. Borgatti, "Centrality and Network Flow," Social Networks 27, no. 1 (2005): 55-71, https://doi.org/10.1016/j.socnet.2004.11.008. 
${ }^{38}$ Ronald S. Burt, "Structural Holes: The Social Structure of Competition" (Cambridge: Harvard University Press, 1992).

${ }^{39}$ Adler and Kwon, "Social Capital," 17-40.

40 Peter V. Marsden and K. E. Campbell, "Reflections on Conceptualizing and Measuring Tie Strength," Social Forces 91, no. 1 (2012): 17-23, https://doi.org/10.1093/sf/sos112tti; Stephen P. Borgatti and R. Cross, "A Relational View of Information Seeking and Learning in Social Networks," Management Science 49, no. 4 (2003): 432-45, https://doi.org/10.1287/mnsc.49.4.432.14428; Peter Moran, "Structural vs. Relational Embeddedness," 1129-51; Mesch Gustavo and I. Talmud, "The Quality of Online and Offline Relationships: The Role of Multiplexity and Duration of Social Relationships," The Information Society 22, no. 3 (2006): 137-48, https://doi.org/10.1080/01972240600677805.

${ }^{41}$ Camille Grange and I. Benbasat, "Opinion Seeking in a Social Network-Enabled Product Review Website: A Study of Word-of-Mouth in the Era of Digital Social Networks," Social Science Electronic Publishing 27, no. 6 (2018): 629-53, https://doi.org/10.2139/ssrn.2993427.

42 Borgatti and Cross, "A Relational View of Information Seeking and Learning in Social Networks," 432-45; Gustavo and Talmud, "The Quality of Online and Offline Relationships," 137-48; Fox and Anderegg, "Romantic Relationship Stages and Social Networking Sites," 685-91; Gray, Parise, and Iyer, "Innovation Impacts of Using Social Bookmarking Systems," 629-43.

43 David Gefen, "E-commerce: The Role of Familiarity and Trust," OMEGA 28, no. 6 (2000): 725-37, https://doi.org/10.1016/S0305-0483(00)00021-9.

44 Tam Kar Yan and S. Y. Ho, “Understanding the Impact of Web Personalization on User Information Processing and Decision Outcomes," MIS Quarterly 30, no. 4 (2006): 865-90, https://doi.org/10.2307/25148757.

45 Jacqueline Johnson Brown and Peter H. Reingen, "Social Ties and Word-of-Mouth Referral Behavior," Journal of Consumer Research 14, no. 3 (December 1987): 350-62, https://doi.org/10.1086/209118.

${ }^{46}$ Glenn J. Browne, Mitzi G. Pitts, and James C. Wetherbe, “Cognitive Stopping Rules for Terminating Information Search in Online Tasks," MIS Quarterly 31 (March 2007): 89-104, https://doi.org/10.2307/25148782.

${ }^{47}$ Yue Long and Yi-Yang Liu, "Propagation Characteristics and Paths of Negative Network Public Opinions in Colleges Under the New Media Environment," Information Science 37, no. 12 (2019): 134-39, https://doi.org/10.13833/j.issn.1007-7634.2019.12.022. 